\title{
Intestinal Parasites Infestation among People Living with HIV under Antiretroviral Therapy in Peri-urban Area of Yaoundé, Cameroon
}

\author{
Christian Ngounouh Taheu, Christelle Diane Tchumtchoua Meliedje, Gilbert Gauthier Bong Bong, \\ Julienne Louise Ngo Likeng, Fabrice Mbakop Ghomsi, Abel Fils Nkoth, \\ Philippe Salomon Nguwoh, and Joseph Fokam
}

\section{ABSTRACT}

Introduction: Human Immunodeficiency Virus (HIV) targets the body's defense system and leads to a decrease in CD4 T-cells in lymphoid tissues associated with intestinal mucosa, leading to an imbalance in the gastrointestinal tract. This study was performed to determine the intestinal parasites infestation among people living with HIV (PLHIV) in peri-urban area in Yaoundé, Cameroon.

Methods: A retro-prospective, prospective, and descriptive study was carried out from January-March 2017 to the Care Unit of the Nkolondom II Catholic Medical Center in Yaoundé on 96 PLHIV after providing informed consent. On each stool sample collected, intestinal parasites testing was performed by using direct examination with physiological saline and Lugol's iodine, Ritchie's technique (formol/ether, 10\%) and by Ziehl-Neelsen staining. Statistical analysis was performed by using SPSS version 17 software, with all $P<0.05$ considered statistically significant.

Results: A total of $52.08 \%(50 / 96)$ were infested with various parasites: Cryptosporidium parvum (72.88\%), Cyclospora cayetanensis $\mathbf{( 1 0 . 1 7 \% ) ,}$ Entamoeba histolytica (8.47\%), Entamoeba coli (5.08\%), Ascaris lumbricoüdes $(1.70 \%)$ and Giardia lamblia $(1.70 \%)$. Parasite's prevalence was more observed in women $(74.00 \%$; 37/50) compared with men $(26.00 \%$ [13/50]). Depending on immunity, immuno-compromised patients (CD4 count $\leq 500$ cells $/ \mathrm{mm}^{3}$ ) were more infested $(82.00 \% ; 41 / 50)$ versus (vs) $18.00 \%$ (9/50), OR: 1.60 (95\% CI: 0.60-4.60).

Conclusion: Intestinal parasites infestation is reported to be high among people under ART in Cameroon's Yaoundé locality, with Cryptosporidium parvum being the predominant circulating species in this locality.

Keywords: ART, Infestation, intestinal parasites, Peri-urban, PLHIV, Yaoundé.
Submitted : Jun 11, 2021

Published : July 20, 2021

ISSN: 2593-8339

DOI: 10.24018 / ejmed.2021.3.4.929

Christian Ngounouh Taheu*

Department of Microbiology, Higher Institute of Sciences and Techniques Applied to Health of the University of Douala, Yaoundé, Cameroon.

(e-mail: taheuchristian@gmail.com)

Christelle Diane Tchumtchoua Meliedje

Department of Microbiology, Higher Institute of Sciences and Techniques Applied to Health of the University of Douala, Yaoundé, Cameroon.

(e-mail: cmeliedje@yahoo.com)

Gilbert Gauthier Bong Bong

Department of Microbiology, Higher Institute of Sciences and Techniques Applied to Health of the University of Douala, Yaoundé, Cameroon.

(e-mail: bongbonggilbert ${ }^{\circledR}$ gmail.com) Julienne Louise Ngo Likeng

Department of Public Health, School of Health Sciences of the Catholic University of Central Africa, Yaoundé, Cameroon.

(e-mail: likeng12@yahoo.com)

Fabrice Mbakop Ghomsi

Nkolondom II Catholic Medical Center, Care Unit, YaoundéCameroon

(e-mail: fabriceghomsi@hotmail.com) Abel Fils Nkoth

Department of Microbiology and Parasitology, University of Buea, Cameroon.

(e-mail: afnkoth ${ }^{@}$ yahoo.fr) Philippe Salomon Nguwoh

Department of Quality Control, National Public Health Laboratory, Yaoundé, Cameroon.

(e-mail:

philippesalomonguwoh@gmail.com)

Joseph Fokam

University of Buea, faculty of Health

Sciences, Buea,Cameroon.

(e-mail: josephfokam@ @mail.com)

*Corresponding Author 


\section{INTRODUCTION}

Epidemiological surveillance data shows that an estimated 2.1 million people are newly infected with HIV, a total of 36.7 million people are living with HIV at the end of 2015 and about 20.9 million people were accessing antiretroviral therapy (ART) [1]. Moreover, it is also believed that an average of 1.1 million people die annually because of Acquired Immune Deficiency Syndrome (AIDS) worldwide [1]. In addition, sub-Saharan Africa (SSA), where about 25.6 million people were living with HIV in 2015 , remains the most affected region. It also accounts for nearly two-thirds of new infections worldwide [1]. However, the failure of the immune system that it causes leads to the appearance of several opportunistic diseases such as Mycobacterium tuberculosis, malaria, cancers and intestinal parasitosis [2].

It is estimated that as much as $60 \%$ of the World's population is infected with intestinal parasites, which may play a significant role in morbidity due to intestinal infections [3]. Intestinal parasitic infections are among the most common infections worldwide. It is estimated that about 3.5 billion people are affected, and about 450 million are ill as a result of these infections [4]. The rate of infection is remarkably high in SSA, where the majority of HIV and AIDS cases are concentrated [5]. The incidence of intestinal parasitic infections is $50 \%$ in developed countries, whereas it reaches up to $95 \%$ in developing countries. These infections are caused both by protozoa and helminths and the main clinical manifestation of the disease caused by them is diarrhea [6]. Diarrheal diseases are important causes of morbidity and mortality in all age groups, but immunocompromised patients and children suffer from more frequent and severe diseases [7]. Moreover, diarrheal diseases are one of the most common gastrointestinal manifestations clinically observable in AIDS patients, occurring at an advanced stage of HIV infection; usually due to opportunistic infections [8]. These opportunistic infections are the immediate consequences of severe immuno-suppression, are responsible for serious illnesses that can lead to death. Among these diseases, intestinal parasites are the main cause of severe chronic diarrhea [9]. Coccidia (Cryptosporidium parvum, Isospora belli, Cyclospora sp) and amoebae (Entamoeba histolytica, Entamoeba coli, etc.) are the etiologic agents commonly responsible for the genesis of these intestinal protozoans in HIV-positive persons worldwide [10].

In Cameroon, intestinal parasites are widespread due to low availability of drinking water in urban, peri-urban and rural areas and other unhygienic factors that increase the risk of infection. These infections are also seen in patients with HIV infection and advanced disease. There is very little national data available on the prevalence of intestinal infections in HIV-positive patients receiving ART. A study conducted in 207 patients treated at the Agreed Treatment Center (ATC) at Yaoundé Central Hospital diagnosed various parasites in the stool: Entamoeba coli (22.68\%), Ascaris lumbricoïdes (22.68\%), Entamoeba histolytica (15.93\%), Crystosporidium spp (12.60\%), Isospora belli (10.08\%), Trichuris trichura (7.60\%), Strongyloides stercoralis (5.88\%), Ankylostoma duodenale/Necator ameracanus $(2.52 \%)$ [11]. The objective of our study was to determine the intestinal parasites infestation among people living with HIV/AIDS under antiretroviral therapy in periurban area in Yaoundé, Cameroon.

\section{MATERIALS AND METhodS}

\section{A. Study Setting and Population}

A retro-prospective, prospective, and descriptive study was carried out from January to March 2017 to the Care Unit of the Nkolondom II Catholic Medical Center in Yaoundé on 96 participants. Catholic Medical Center of Nkolondom II is located in the Center region, Mfoundi department, district of Yaoundé I, Nkolondom district, Messassi crossroads. In terms of health, it belongs to the Health District of Ndjoungolo and consists of a health center, a maternity unit and a care unit called "DREAM center".

\section{B. Ethical Consideration/Consent}

Administrative authorization, principal agreement $\left(\mathrm{N}^{\circ}\right.$ 000353/AP/MINSANTE/SG/DRSPC) was issued and ethical clearance for the study was obtained from the Institutional Review Board (IRB) of the Centre Regional Ethics Committee for Human Health Research (reference: $\mathrm{CEN}^{\circ}$ 00166/CRERSHC/2017). Moreover, we obtained the authorization from the administrators of the Nkolondom II Catholic Medical Center. At the ART recruitment site, an information note was administered to the eligible participants, who then provided their written informed consent prior to enrollment into the study.

\section{Enrollment of Participants and Specimen Collected}

All participants enrolled in the study were living with HIV under ART and have been recruited consecutively. An interview with a standard questionnaire containing sociodemographic data was used to register the study participants. CD4 T-cell, type of protocol, duration of treatment and cotrimoxazole prophylaxis were obtained from medical records of the study participants. The written informed consent from all the participants was obtained. The stool was freshly collected in sterile, labeled plastic vials. The samples were returned to the laboratory as soon as possible for examination. Since the coprology examination was not part of the follow-up assessment of patients on ART, it was systematically requested from each participant in the study of the coprology and the concentration examination by the physician.

\section{Stool Examination}

1) Direct Examination with Physiological Water and Lugol

Stool samples were firstly observed macroscopically for the presence of mucus, blood and adult helminthes worms. After labeling the slide, a drop of saline water and lugol were placed on the slide. Using a wooden applicator, a small quantity of stool was taken and mixed with the drop of saline water and lugol. Then we covered with the coverslide and read the slides under an optical microscope at the objectives $\times 10$ then at $\times 40$. 


\section{2) Ritchie Concentration Technique}

We first proceeded by gradually diluting a stool volume in 10 volumes of $10 \%$ formalin in a tube until a homogeneous mixture was obtained. After allowing settling for one minute, we sieved $2 / 3$ of the mixture in a conical tube. We then added ether in the proportion of $1 / 3$. Then, we closed and shaken by hand by successive turns for 30 seconds. At the end of this time, we centrifuged for 5 minutes at $1500 \mathrm{rpm}$ to eliminate the three upper layers by inversion. The pellet was read drop by drop between the slide and the coverslide under the light microscope at the objectives $\times 10$ then at $\times 40$.

\section{3) Exam after Modified Neelsen Ziehl Staining}

On a clean slide, a thin smear of the stool was made and dried on a rack. After fixing to the alcohol at $95{ }^{\circ} \mathrm{C}$ for 5 minutes, the slide was dried again using a dryer for about 2 minutes. The preparation was then covered with filtered Ziehl fuchsine and placed on a staining medium for 5 minutes. The slide was rinsed with tap water until all the fuchsine was removed and then bleached with a solution of $3 \%$ hydrochloric acid mixed with $95 \%$ ethanol, rinsing each time with tap water. Counterstaining was performed by soaking the preparation in a $0.25 \%$ malachite green solution for 30 seconds. After rinsing with tap water, the slide was dried and then read under a microscope with the immersion oil (objective $\times 100$ ).

\section{E. Data Collection and Statistical Analysis}

Data were collected using a standard questionnaire, then abstracted in a Microsoft excel version 2007 spread sheet. Data were then entered into, analyzed with Statistical Package for Social Sciences (SPSS) version 17. Statistical association was performed using Chi square and Fisher Exact test where appropriate, with corresponding 95\% CI. pvalue was considered statistically significant for all $\mathrm{p}<0.05$.

\section{RESULTS}

A. Socio-demographic Characteristics of Study Population

A total of 96 on 141 participants $(68.08 \%)$ were enrolled in our study with a female predominance of $75.00 \%(72 / 96)$ against $25.00 \%(24 / 96)$ for the male with the sex ratio $(\mathrm{M} / \mathrm{F})$ of 0.3 i.e., one (01) man for three (03) female (1/3). The mean age of participants was $37.58 \pm 10.58$ years (min-max: 19-69 years old [IQR: $30-45]$ ) and the most represented age group was $30-40$ years old with $42.71 \%$ (41/96). In terms of marital status, married were more represented with $57.29 \%$ (55/96) followed by single, with $36.46 \%$ (35/96).

\section{B. Prevalence of Parasitic Species}

The prevalence of parasitic species is shown in TABLE I. Out of 96 participants enrolled in this study, 61.46\% (59/96) of parasites were isolated. The most common parasites were the oocysts of Cryptosporidium parvum $(72.88 \% ; 43 / 59)$ and Cyclospora cayetanensis $(10.17 \% ; 6 / 59)$. The most found Protozoan were Entamoeba histolytica, Entamoeba coli and Giardia lamblia with respective rates of $8.47 \%$ (5/59), 5.08\% (3/59) and 1.70\% (1/59). Moreover, Ascaris lumbricoides was the helminths only found with $1.70 \%$ $(1 / 59)$.

\begin{tabular}{ccc}
\multicolumn{2}{c}{ TABLE I: PREVALENCE OF PARASITIC SPECIES } \\
\hline Intestinal parasites & \multicolumn{2}{c}{$\begin{array}{c}\text { Total number of isolated } \\
\text { parasites }(\mathrm{n}=59)\end{array}$} \\
\cline { 2 - 3 } & Frequency & $\begin{array}{c}\text { Percentage } \\
(\%)\end{array}$ \\
\hline Cryptosporidium parvum & 43 & 72.88 \\
Cyclospora cayetanensis & 06 & 10.17 \\
Entamoeba histolytica & 05 & 08.47 \\
Entamoeba coli & 03 & 05.08 \\
Giardia lamblia & 01 & 01.70 \\
Ascaris lumbricoïdes & 01 & 01.70 \\
\hline
\end{tabular}

$\mathrm{n}$ : frequency; \%: percentage.

\section{Distribution of Socio-demographic Characteristics according to Infestation}

The distribution of socio-demographic characteristics according to infestation is shown in Table II. Globally, $52.08 \%(50 / 96)$ were infested with various parasites with predominance in women $(74.00 \% ; 37 / 50)$ vs. $26.00 \%$ $(13 / 50)$ for men. The age group 30-40 years was more infested $(42.00 \% ; 21 / 50)$ followed by those aged $41-51$ years $(24.00 \% ; 12 / 50)$. The marital status of the participants shows that the married were more infested with $62.00 \%$ $(31 / 50)$ followed by singles with $32.00 \%$ (16/50).

\begin{tabular}{|c|c|c|c|c|c|}
\hline TABLE II: DIST & UTION OF SOC & DEMOGRAP & S CHARACTERISTI & ACCORDING TO IN & \multirow{3}{*}{$\mathrm{p}$-value } \\
\hline \multirow[t]{2}{*}{ Variables } & $\begin{array}{c}\text { Total } \\
(\mathrm{N}=96)\end{array}$ & $\begin{array}{c}\text { Infestation } \\
(\mathrm{n}=50)\end{array}$ & $\begin{array}{c}\text { Non infestation } \\
(\mathrm{n}=46)\end{array}$ & \multirow[t]{2}{*}{ OR $(95 \% \mathrm{CI})$} & \\
\hline & $\mathrm{n}(\%)$ & $\mathrm{n}(\%)$ & $\mathrm{n}(\%)$ & & \\
\hline \multicolumn{6}{|l|}{ Gender } \\
\hline Female & $72(75.00)$ & 37 (51.39) & $35(48.61)$ & $0.89(0.3-2.2)$ & 0.81 \\
\hline Male & $24(25.00)$ & $13(54.17)$ & $11(45.83)$ & & \\
\hline \multicolumn{6}{|l|}{ Age (years) } \\
\hline $19-29$ & $23(23.95)$ & 09 (39.13) & $14(60.87)$ & $0.50(0.19-1.30)$ & 0.15 \\
\hline $30-40$ & $41(42.71)$ & $21(51.22)$ & $20(48.78)$ & $0.94(0.41-2.11)$ & 0.88 \\
\hline $41-51$ & $21(21.88)$ & $12(57.14)$ & $09(42.86)$ & $1.29(0.48-3.44)$ & 0.60 \\
\hline $52-62$ & $09(09.38)$ & 07 (77.78) & $02(22.22)$ & $\begin{array}{c}3.58(0.70- \\
18.21)\end{array}$ & 0.20 \\
\hline$\geq 63$ & $02(02.08)$ & $01(50.00)$ & $01(50.00)$ & $\begin{array}{c}0.91(0.05- \\
15.12)\end{array}$ & 1.00 \\
\hline \multicolumn{6}{|l|}{ Marital Status } \\
\hline Single & $35(36.46)$ & $16(45.71)$ & $19(54.29)$ & $0.66(0.29-1.54)$ & 0.34 \\
\hline Married & $55(57.29)$ & $31(56.36)$ & $24(43.64)$ & $1.49(0.66-3.37)$ & 0.33 \\
\hline Widowed & $06(06.25)$ & $03(50.00)$ & $03(50.00)$ & $0.91(0.17-4.77)$ & 1.00 \\
\hline
\end{tabular}




\section{Infestation according to the CD4 T-cells Count and the Type of Protocol}

The infestation according to the CD4 T-cells count and the type of protocol is shown in Table III. According to immunity, study participants with immune-suppression (CD4 count $\leq 500$ cells $/ \mathrm{mm}^{3}$ ) were more infested by various parasites with $82.00 \%(41 / 50)$ vs. $18.00 \%(9 / 50)$ for those with a CD4 count $>500$ cells $/ \mathrm{mm}^{3}$ (OR: 1.60 ; 95\%CI: 0.60 $4.60, \mathrm{p}=0.34)$. The infestation was higher in the participants under first-line antiretroviral therapy $(98.00 \% ; 49 / 50)$ vs. $2.00 \%(1 / 50)$ in the second line).

\section{E. Infestation according to the Duration of ART and Cotrimoxazole Prophylaxis}

The infestation according to the duration of ART and cotrimoxazole prophylaxis is shown in Table IV. According to the duration of ART, a decrease in the infestation rate was observed: from $38.00 \%$ (19/50) to less than three months to $14.00 \%(7 / 50)$ after 18 months $(\mathrm{p}=0.66)$. Based on cotrimoxazole prophylaxis, $52.00 \%(26 / 50)$ of participants under cotrimoxazole and $48.00 \%$ (24/50) of those without cotrimoxazole were infested.

\section{DISCUSSION}

The objective of this study was to determine intestinal parasites infestation among patients living with HIV (PLHIV) under antiretroviral therapy (ART). The overall intestinal parasites infestation was $52.08 \%$ (50/96). This result is similar with many studies carried out in Cameroon on the prevalence of intestinal parasites in people living with HIV/AIDS by: Vouking and collaborator [11] at the Agreed Treatment Center of Yaoundé Central Hospital and Nkenfou and collaborator [12] in the Western Region in the city of Dschang with $57.48 \%$ and $59.50 \%$ respectively. However, it is higher than the survey carried out by Safarti and collaborator [13] in Yaoundé and Lehman and collaborator [14] in Douala, who found $33 \%$ and $27.80 \%$ respectively.
This result obtained in this study $(52.08 \%)$ confirms the observations of many authors according to which intestinal parasites occupy an important place among the diseases of the gastrointestinal tract in people in general and people infected in particular by HIV in the developing countries [15], [16]. This rate of infestation observed in our study could be explained by the fact that poverty and precariousness still make the daily lives of many families in underdeveloped countries leading to lack of drinking water and food hygiene.

According to immunity, participants with immunodeficiency (number of CD4 T-cells $\leq 500$ cells $/ \mathrm{mm}^{3}$ ) were more infested with various parasites: $82.00 \%(41 / 50)$ compared to $18.00 \%$ (9/50) for those whose CD4 T-cell count was $>500$ cells $/ \mathrm{mm}^{3}$. This finding is reliable with those of Assefa and collaborator [17] in Ethiopia and Ghimire and collaborator [18] in Nepal who showed that intestinal parasite infestation rate is observed in patients with immuno-suppression. This could be explained by late detection of PLHIV resulting in late management of the infection, and advanced development of the infection. A similar study in northern Ethiopia found that parasitic infections were common among HIV/AIDS patients on antiretroviral therapy and that the risk of becoming infected decreased with increasing CD4 counts and some behavioral factors [19].

Infestation was higher among participants on first-line treatment $(98.00 \% ; 49 / 50)$ versus $2.00 \%$ (1/50) for those on the second line. This high infestation rate could be explained by the eligibility criteria for antiretroviral treatment, the inaccessibility of healthcare services and poverty. In addition, the rate of infestation decreased with the duration of antiretroviral therapy, from $38.00 \%(19 / 50)$ to less than three months to $14.00 \%$ (7/50) after 18 months. This observation could be explained by the new UNAIDS guidelines "test and treat" on the early treatment of any person infected with HIV in order to reach the 90-90-90 target [20].

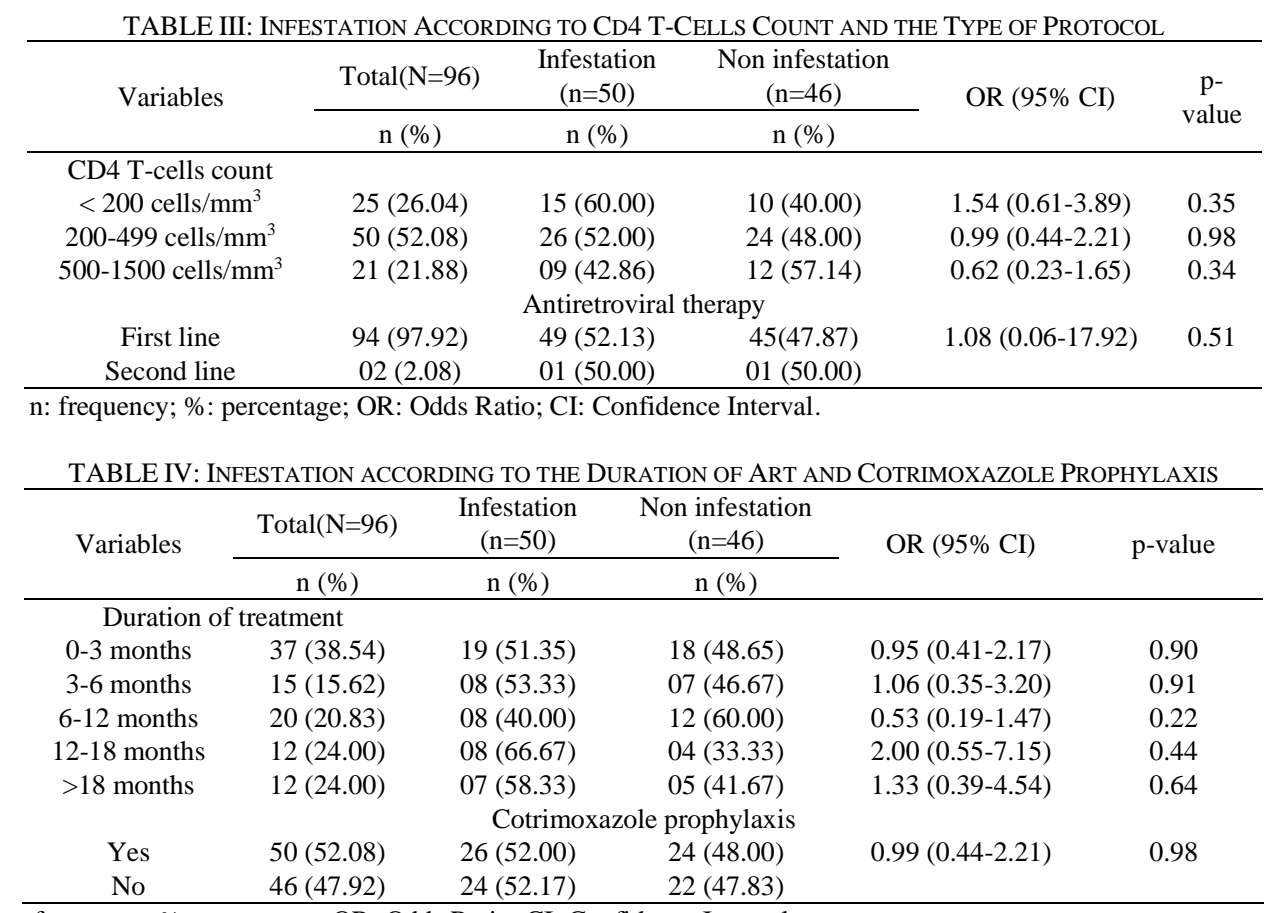

$\mathrm{n}$ : frequency; \%: percentage; OR: Odds Ratio; CI: Confidence Interval. 
Intestinal parasites are a diverse group of microorganisms including unicellular protozoa and multicellular intestinal worms capable of disrupting nutrient uptake. Moreover, apart from the effects of HIV enteropathy, the presence of intestinal parasites is a major contributor to diarrhea, which in the long run could lead to a wasting syndrome called "thin disease" [21]. A total of $61.46 \%$ (59/96) parasites were isolated in our study. The most common protozoa were Entamoeba histolytica, Entamoeba coli and Giardia lamblia, with respective rates of $8.47 \%, 5.08 \%$ and $1.70 \%$. Our results are similar to those obtained by Nkenfou and collaborator [12] who reported the rates of $7.52 \%, 4.04 \%$ and $0.25 \%$ respectively for Entamoeba histolytica, Entamoeba coli and Giardia lamblia. Protozoa are not only opportunistic parasites in patients living with HIV/AIDS but also parasites of the fecal peril due to the scrupulous non respect of the rules of hygiene. For the helminth's eggs, only egg of Ascaris lumbricoides was found in one case with $1.70 \%(1 / 59)$. A systematic review showed that between one third and one half of the world's population was infected with at least one species of helminths, the vast majority of these infections occurring in areas of the world where resources were limited is the most serious [21]. This review suggests that treatment of helminths infection may result in delayed progression of HIV-1 infection as measured by changes in CD4 count and plasma viral load [13]. Of the opportunistic intestinal parasites, Cryptosporidium parvum was mostly found with $72.88 \%$ (43/59). Our data are largely above the results of many studies carried out in Cameroon by: Vouking and collaborator [11], Lehman and collaborator [14] and Nkenfou and collaborator [12] who found respectively $12.60 \%, 7.40 \%$, and $19.04 \%$. Cyclospora cayetanensis is another opportunistic parasite and its frequency obtained in our study was $10.17 \%$ (6/59). This rate is higher than that reported by Paboriboune and collaborator [22] which was $2.2 \%$ suggesting the surveillance of intestinal parasites infestation people living with HIV under antiretroviral therapy (ART) using the techniques of concentration and Ziehl Neelsen method as a routine biological examination.

\section{CONCLUSION}

Intestinal parasites infestation is reported to be high among PLHIV under ART in Yaoundé, Cameroon, and Cryptosporidium parvum follow by the Cyclospora cayetanensis were the predominant circulating species in this locality. Depending on the type of antiretroviral protocol, the infestation was higher in the participants under first-line. Immuno-competence and prolonged use of ARVs would protect against this infestation. In the era of "Test \& Treat", more advanced observations would allow a better monitoring PLHIV under ART.

\section{RECOMMENDATION}

Regarding the research technique, the direct detection by optical microscopy is not effective for all digestive parasites. Other special techniques would have been needed to overcome the limits of parasitic coprology (for example:
KATO-KATZ technique, Trichome MASSON staining, etc.). Moreover, the small sample size did not allow us to have statistically significant results. So, the study needs to be expanded to a wide population in other zone in entire country.

\section{ACKNOWLEDGEMENTS}

The authors would like to acknowledge the support and facility provided by the staffs of Catholic Medical Center of Nkolondom II and all the participants without whom this research would not have been possible.

\section{REFERENCES}

[1] Global health estimates 2015: deaths by cause, age, sex, by country and by region, 2000-2015. Geneva: World Health Organization; 2016.

[2] F. Veas, J.P. Rey, (1991). Infection à VIH et parasitoses en zone tropicale. Cahiers Santé 1: 189-201.

[3] World Health Organization (WHO). Prevention and Control of Intestinal parasitic Infections. WHO Technical Report.749: 1-86. 1987.

[4] WHO, World Health Organization. Control of Tropical Diseases WHO, Geneva. 1998.

[5] UNAIDS/ WHO HIV Epidemic Update. Geneva. UNAIDS, 2002

[6] E. Chacon-Cruz, (2003). Intestinal Protozoal Diseases. eMedicine J. 3(5): sec. 1-11.

[7] R.A. Giannella, (1993). Gastroenterology Clinics of North America: Acute Infectious Diarrhoea. W.B. Saunders Company, Philadelphia. 22 (3):483622.

[8] B. Fisseha, B. Petros, T. Woldemichael, H. Mohammed, (1999) Diarrhoea-associated Parasitic Infectious Agents in AIDS Patients within Selected Addis Ababa Hospitals. Ethiop. J. Health Dev. 13(3): 169-173.

[9] A. Konaté, D. Minta, M. Diarra, A. Dolo, M. Dembele, B. Diarra, M.Y. Maiga, H.A. Traore, \& O. Doumbo, (2005). Parasitoses digestives au cours de la diarrhée du sida. Bull Soc Pathol Exot, 98, 1, 33-35. [PubMed].

[10] I.M. Ekejindu, P.U Ele, S.O. Okonkwo, O.C. Ezenwagu, D.A Ezeagwuna, (2010). Intestinal parasitic infection among HIVseropositive and HIV-seronegative individuals at Nnewi, South Eastern Nigeria. World Journal of Medical Sciences. 5:71-73.

[11] Z.M. Vouking, P. Enoka, C.V. Tamo, and N.C. Tadenfok, (2014) Prevalence of intestinal parasites among HIV patients at the Yaoundé Central Hospital, Cameroon. Pan Afr Med J. 18: 136. Published online 2014 Jun 11. doi: 10.11604/pamj.2014.18.136.3052.

[12] C.N. Nkenfou, C.T. Nana, V.K. Payne, (2013). Intestinal parasitic infections in HIV infected and non-infected patients in a low HIV prevalence region, West-Cameroon. PLoS One 2013;8 (2):e57914. doi: 10.1371/journal.pone.0057914. [PMC free article] [PubMed] [CrossRef].

[13] C. Sarfati, A. Bourgeois, J. Menotti, F. Liegeois, R. Moyou-Somo, E. Delaporte, F. Derouin, E.M. Ngole, J.M. Molina, (2006). Prevalence of intestinal parasites including microsporidia in human immunodeficiency virus-infected adults in Cameroon: A crosssectional study. American Journal of Tropical Medicine and Hygiene, Jan; 74(1):162-164. [PubMed].

[14] L.G. Lehman, L. Kangam, E. Nguepi, M.L. Mbenoun, and C.F Bilong Bilong, (2012). Study of intestinal parasitic infections associated with HIV infection in Douala, Cameroon. Retrovirology. 9 (Suppl 1): P48. 2012. Published online 2012 May 25. doi: 10.1186/1742-4690-9-S1-P48.

[15] Y. Alfonso, L. Monzonto, (2011). Inhibiteurs de la protéase du VIH effets sur les parasites opportunistes du protozoaire. Open Med Chem. 2011; 5: 40-50. Pubmed Google Scholar.

[16] L. Chancin-Bonilla, A.P. Panunzio, F.M. Monsalve-Castillo, I.E Parra-Cepeda, R.Martinez, (2006). Microsporidiose au Venezuela: prévalence de la microsporidiose intestinale contribution à la diarrhée chez un groupe de patients infectés par le VIH dans l'état de Zulia. Suis J Trop Med Hyg. 2006 mars; 74 (3): 482-6. Pubmed Google Scholar.

[17] S. Assefa, B. Erko, G. Medhin, Z. Assefa, T. Shimelis, (2009). Intestinal parasitic infections in relation to HIV/AIDS status, diarrhea and CD4 T-cell count. BMC Infect Dis. Sep 18; 9:155. doi: 
10.1186/1471-2334-9-155. [PMC free article] [PubMed].

[18] A. Ghimire, S. Bhandari, S. Tandukar, J. Amatya, D. BhandarI, J.B Sherchand, (2016). Enteric parasitic infection among HIV infected patients visiting Tribhuvan University Teaching Hospital, Nepal. BMC Res Notes; 9:204-207.

[19] A. Alemu, Y. Shiferaw, G. Getnet, A. Yalew, Z. Addis, (2011) Opportunistic and other intestinal parasites among HIV/AIDS patients attending Gambi higher clinic in Bahir Dar city, North West Ethiopia. Asian Pac J Trop Med. Aug; 4(8):661-665.

[20] ONUSIDA. Rapport d'activité sur la riposte au SIDA dans le monde 2012 : Directives d'indicateurs de base pour le suivi de la déclaration politique sur le VIH/SIDA de 2011, Genève. (http://www.unaids.org/tn).

[21] A. Gassama, B. Thiaw, N.M. Dia, F. Fall, P. Camara, P. Hovette, J.L. Perret, A. Gueye-Ndiaye, S. Mboup, P.S. Sow, A. Aidara-Kane, (2001). Infective etiology of diarrhea in adults with HIV infection in Dakar: a case-control study on 594 patients. Dakar Med. 46(1):46-50 [PubMed].

[22] P. Paboriboune, N. Phoumindr, E. Borel, K. Sourinphoumy, S. Phaxayaseng, E. Luangkhot, (2014). Intestinal parasitic infections in HIV-infected patients, Lao People's Democratic Republic. PLoS One; 9:e91452. 